\title{
Estudios arqueometalúrgicos sobre objetos del sitio Falda del Cerro (Catamarca, Argentina)
}

\author{
Archaeometallurgical studies about objects of Falda \\ del Cerro site (Catamarca, Argentina)
}

Marianela Taboada ${ }^{1}$

\author{
${ }^{1}$ IDECU, Universidad de Buenos Aires, CONICET, Museo Etnográfico. Moreno 350 CP: 1091. Ciudad de Buenos \\ Aires, Argentina. \\ e-mail: taboadamarianela@gmail.com
}

\section{RESUMEN}

Falda del Cerro es un yacimiento arqueológico ubicado en la falda occidental del Aconquija (Provincia de Catamarca) [1], cuya ocupación humana está datada radiocarbónicamente en los primeros siglos d.C. [2]. El sitio presenta recintos circulares y subcirculares construidos con paredes de rocas cuyos cimientos se encuentran cavados en la roca madre. La cerámica asociada al sitio corresponde a estilos característicos de la época: Alpatauca, Gris Pulido, Ante Pulido, Condorhuasi, etc.

En las recolecciones superficiales realizadas en el área y dentro de los contextos excavados en el sitio se han encontrado fragmentos de cerámica con evidencia de vitrificación, restos de minerales (posiblemente utilizados como materia prima), escoria y objetos metálicos [3]. Estas evidencias nos hacen suponer que en Falda del Cerro se llevaron a cabo actividades relacionadas con la producción metalúrgica.

El trabajo se focaliza en seis objetos metálicos hallados en el yacimiento y tiene por objetivo su caracterización para determinar las similitudes o diferencias químicas existentes entre ellos. Para ello, se realizaron análisis de Dispersión de Energía de Rayos X (EDAX) para lograr la caracterización química de la muestra. Estos datos permitirán identificar la existencia de una o varias formas de manufacturar los bienes metálicos en el área de estudio.

Este estudio preliminar procura iniciar la investigación sobre la chaîne opératoire de la producción metalúrgica al sur de los valles Calchaquíes durante el primer milenio d.C. Las investigaciones posteriores apuntarán al estudio de los restos minerales hallados en el sitio y a la exploración de posibles fuentes de aprovisionamiento.

Palabras clave: Cobre, metalurgia, prehispánico, Noroeste argentino.

\begin{abstract}
Falda del Cerro is an archaeological site located on the western slope of the Aconquija Mountains (Catamarca, Argentina) [1]. Its human occupation is radiocarbonically dated to the first centuries AD [2]. The site presents circular and semi-circular enclosures constructed with stone walls which foundations are dug into the bedrock. Associated pottery belongs to the period's distinctive styles: Alpatauca, Gris Pulido, Ante Pulido, Condorhuasi, etc.

Surface assemblage and excavated contexts in the area evinced pottery fragments with vitrification evidence on them, mineral remains (probably used as raw material), slag and metal objects [3]. Such evidence led us to suppose that activities related to metallurgic production took place in Falda del Cerro.

The present paper is focused on six metal objects found in the site. Our aim is to characterize these objects in order to determine chemical similarities or differences between them. Energy-dispersive X-ray spectroscopy $(\mathrm{EDAX})$ analyses were made in order to chemically characterize the sample. The obtained data will allow us to identify the existence of metallic production in the studied area.

This preliminary study initiates the research about chaîne opératoire of metallurgical production on the southern Calchaquí valleys during the first millennium A.D. Future investigations will aim to produce the analysis of mineral remains found in the site and to explore the potential sources of raw material.
\end{abstract}


Keywords: Copper, metallurgy, pre-Hispanic, Northwestern Argentina

\section{INTRODUCCIÓN}

En este artículo nos proponemos realizar la caracterización general de objetos metálicos recuperados en los trabajos arqueológicos llevados a cabo en Falda del Cerro. Este sitio se encuentra emplazado en la falda occidental de la Sierra del Aconquija, Provincia de Catamarca, Argentina (66 $15^{\circ} \mathrm{O}-27^{\circ} 15^{\prime} \mathrm{S}$ ) (Figura 1).

En el año 1957, MÁRQUEZ MIRANDA y CIGLIANO [1] realizaron las primeras excavaciones en el área de estudio. Estas investigaciones les permitieron identificar tres sectores ubicados a distintas alturas sobre el conoide de deyección. En la parte inferior $(2800 \mathrm{msnm})$ se encuentra Ingenio del Arenal-Médanos, en la parte media (2800-3150 msnm) Ingenio del Arenal-Centro y en la parte superior (3100 msnm) Ingenio del Arenal-Falda del Cerro. A finales de la década de 1980 SCATTOLIN y WILLIAMS [3] retomaron las investigaciones en los tres sitios. En Falda del Cerro recuperaron fragmentos de minerales cupríferos posiblemente utilizados como materia prima, sedimentos con posibles evidencias de termoalteración, escoria y fragmentos de recipientes cerámicos con evidencias de vitrificación e incrustaciones de escoria. A partir de esta información, las autoras expresaron que posiblemente en el sitio se habían llevado a cabo actividades relacionadas con la fundición de minerales de cobre. Posteriormente, se realizaron nuevas excavaciones con el objetivo de conocer la estratigrafía del sitio, comprender la asociación artefactual, obtener material para realizar dataciones y establecer distinciones funcionales de los recintos excavados. Estos estudios permitieron obtener el

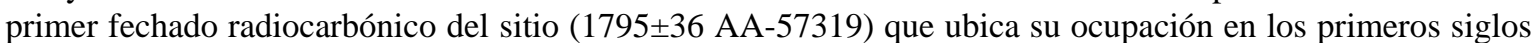
d.C. [4,5]. En los trabajos de campo realizados en los años 2003 y 2014 se recuperaron seis objetos metálicos en los sectores A y B, tres hallados en contexto de excavación y tres en superficie (Figuras 2 y 3). Este hallazgo posibilita examinar estos objetos en relación al entorno en el que posiblemente fueron manufacturados, generando así un corpus de información relevante a la hora de estudiar la metalurgia prehispánica de los primeros siglos d. C.

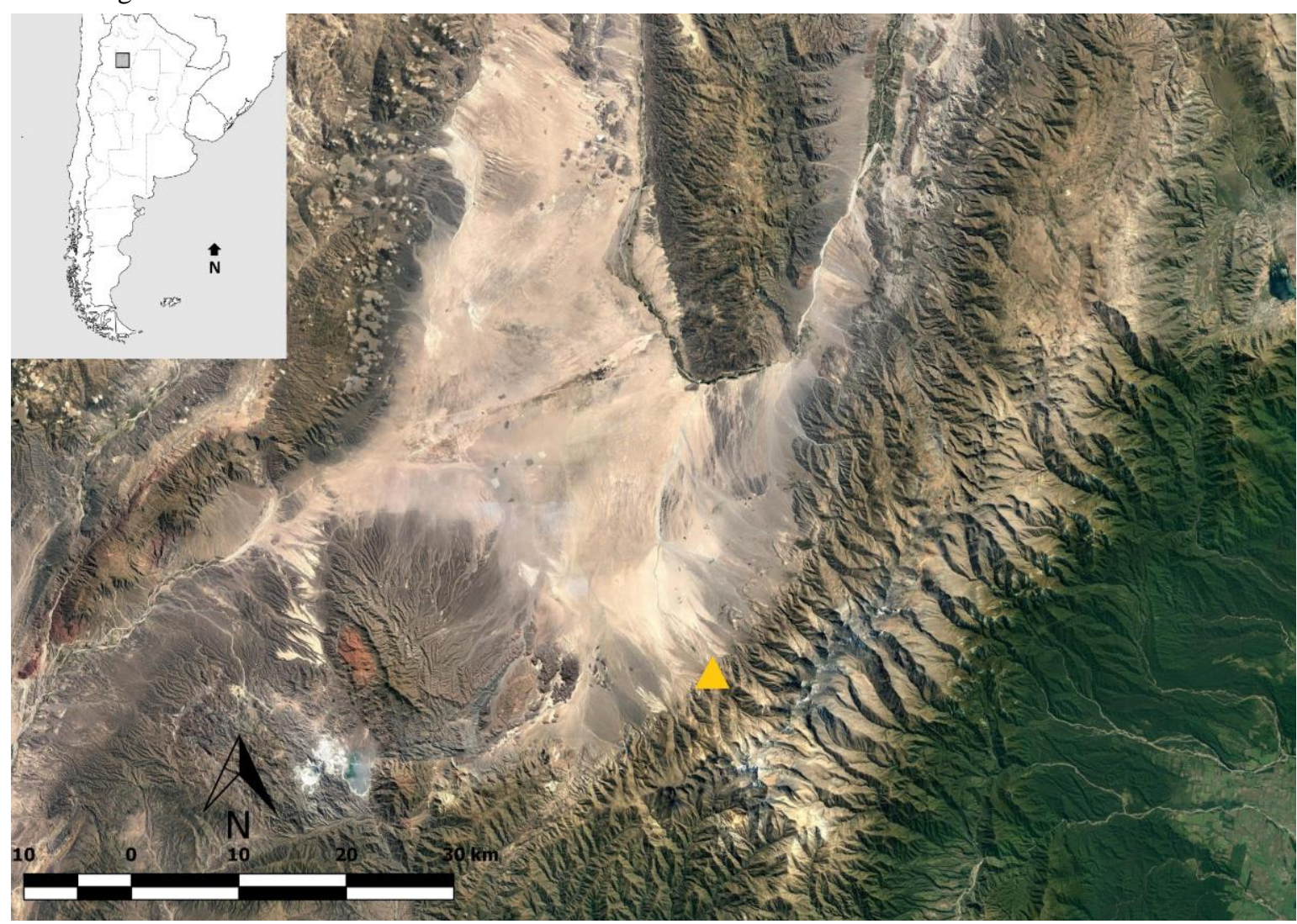

Figura 1: Mapa de ubicación del sitio Falda del Cerro.

La zona comprendida por los valles Calchaquíes cuenta con una trayectoria de estudios arqueológicos que comenzó a fines del siglo XIX. Desde la perspectiva de la arqueometalurgia, AMBROSETTI [6] y luego GONZÁLEZ [7], fueron los primeros en recopilar información sobre objetos metálicos, en su mayoría ornamentos. Varios de estos casos no cuentan con referencias sobre el contexto de asociación ni fechados radio- 
carbónicos, dificultando su estudio en profundidad.

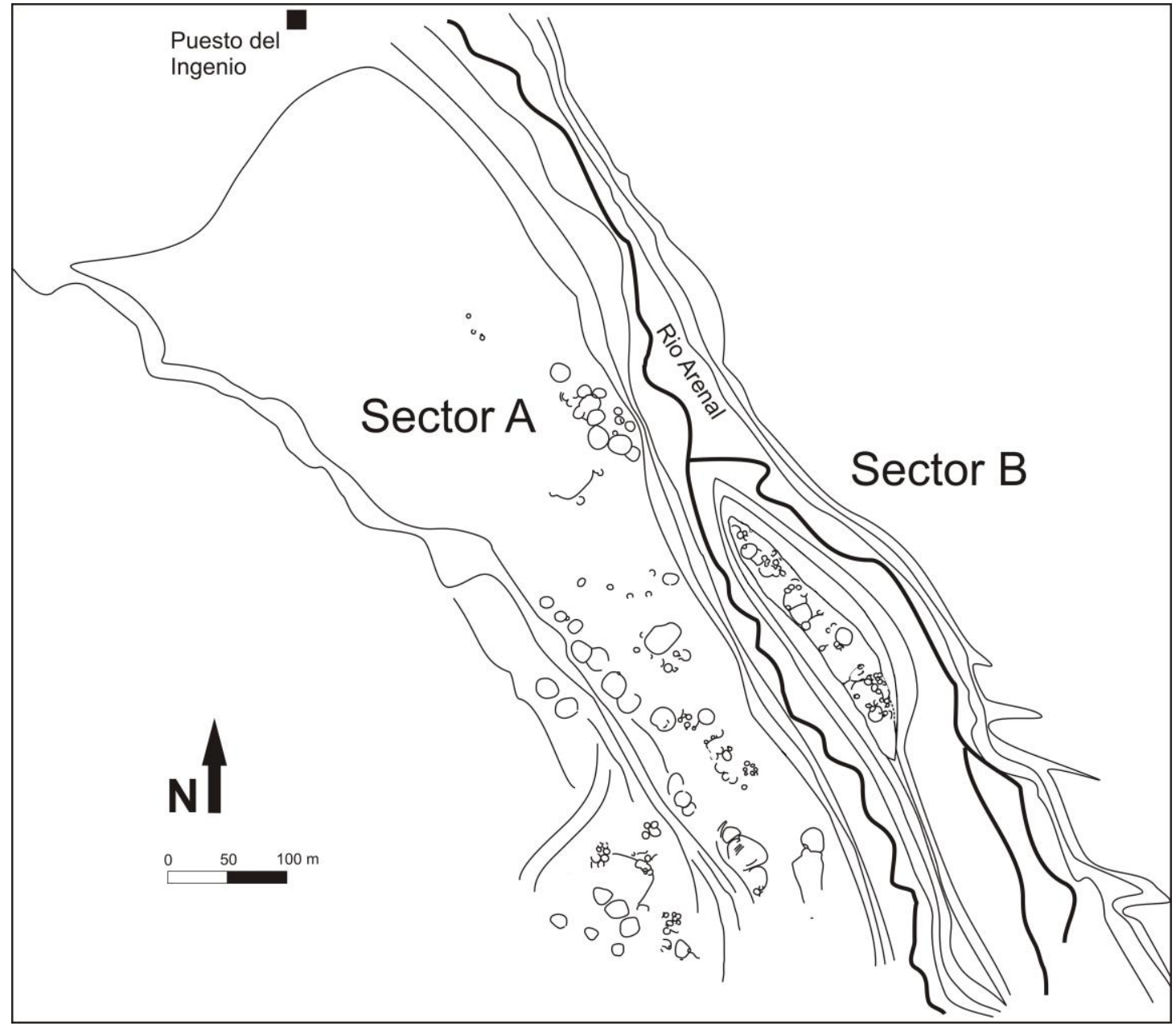

Figura 2. Sectores y estructruras arquitectónicas del sitio.

En los últimos años se han encontrado diversas evidencias de actividad metalúrgica prehispánica asociada a contextos de los períodos Formativo, Integración Regional, Tardío o de Desarrollos Regionales e Inca. En el sitio arqueológico de Bordo Marcial ubicado en el valle del Cajón (La Quebrada, Catamarca), se encontraron las evidencias más tempranas de metalurgia de la zona, una máscara con rasgos antropomorfos y un pendiente, ambos de cobre y asociados a contextos funerarios. Dichos contextos fueron datados por AMS en dientes procedentes de las tumbas y obtuvieron fechados de $3001 \pm 49$ años AP y $3057 \pm 50$ años AP, respectivamente [8].

En los sitios arqueológicos de Alamito (Andalgalá, Catamarca) se recuperaron restos de huayras (hornos), martillos y yunques posiblemente utilizados para la molienda de las materias primas, escoria y alrededor de veinte objetos de cobre [9, 10]. El estudio en profundidad de estos contextos fechados alrededor del 500 d.C. amplió las perspectivas sobre la metalurgia temprana. A diferencia de los objetos hallados en el valle del Cajón, cuyo componente principal es el cobre, en el caso de Alamito, tres objetos presentaron arsénico en distintas proporciones. ANGIORAMA $[9,10]$ señala que para este mismo período el Dr. Luis González analizó objetos provenientes de los sitios Condorhuasi y Ciénaga (valle de Hualfín, Catamarca) detectando posibles elementos aleantes. Analizó la composición química de las fuentes de aprovisionamiento de la zona y corroboró que la presencia de estaño asociada al cobre no aparece en la naturaleza, demostrando un agregado intencional durante el proceso de manufactura para alterar las propiedades del material. Estos datos denotan la especialización técnica de los artesanos que trabajaron metales y apuntan a complejizar la visión de las sociedades que habitaron los valles Calchaquíes alrededor del 500 d.C.

Por otra parte, GONZALEZ [11-15] y GLUZMAN [16, 17] se han abocado a la investigación de contextos de producción metalúrgica de los períodos de Integración Regional (650 d.C. - 850 d.C.), Desarrollos Regionales (850 d.C. - 1480 d.C.) e Inca (1480 d.C. - 1532 d.C.). Ambos autores reconocen la necesidad de 
estudiar a la metalurgia del pasado como un fenómeno sociocultural que involucró tanto relaciones sociales que legitimaron la producción de determinados objetos, como relaciones con el material que fue transformado utilizando técnicas de alta complejidad (manejo de altas temperaturas, construcción de crisoles y moldes, acceso a combustible, etc.) $[11,16,17]$. Los autores han realizado un aporte significativo a la arqueometalurgia del Noroeste argentino desde la teoría y la práctica [12, 13, 14]. Rincón Chico (valle de Santa María o Yocavil, Catamarca) es uno de los sitios estudiados que ha proporcionado una gran cantidad de evidencias sobre actividades metalúrgicas [15]. Los fechados ubican su ocupación en un período comprendido entre los siglos X y XVII d.C. La calidad y cantidad de materiales recuperados es sustancial porque permitió comprender la chaîne opératoire metalúrgica que se llevó a cabo en el sitio. Se han recuperado cubetas de combustión, escorias, sedimentos termoalterados, fragmentos de minerales cupríferos, rodados con evidencia de haber sido sometidos a altas temperaturas, fragmentos de crisoles y moldes, y metal en forma de gotas (posibles restos fundición). Sin embargo, no se hallaron hasta el momento piezas terminadas. Aún así, a partir de las gotas metálicas se pudo determinar que el material utilizado era bronce estañífero. El buen estado de conservación de algunos fragmentos de moldes permitió identificar que se realizaron objetos de alta calidad (por ejemplo, campanas ovales y discos) utilizando distintas técnicas de manufactura, denotando un gran nivel de complejidad y especialización [15]. Ambos autores proponen que durante el Período Tardío o Desarrollos Regionales, la metalurgia pudo haber cumplido un rol legitimador del status social a partir del uso de bienes suntuarios.

Estos trabajos han realizado un aporte valioso y significativo a la arqueometalurgia. Dada la alta complejidad que poseen las técnicas utilizadas en la manufactura de objetos metálicos, junto con el rol social que éstos cumplieron para los habitantes de los valles Calchaquíes, consideramos que el estudio de la metalurgia prehispánica debe enmarcarse dentro de un abordaje holístico y no sólo tecnológico.

En esta oportunidad, se propone realizar la caracterización general de objetos metálicos de Falda del Cerro a partir de la observación de las microestructuras e identificación de las composiciones químicas. A través de esta información, se procura realizar una primera aproximación al proceso de producción metalúrgica en la zona durante los primeros siglos d.C.

\section{MATERIALES Y MÉTODOS}

La muestra está compuesta por seis artefactos recuperados en los sectores A y B del sitio Falda del Cerro (Figuras 2 y 3, Tabla 1). Dadas sus características morfológicas, no hemos podido determinar su funcionalidad. Se seleccionaron los Objetos 1 y 2, recuperados en contexto de excavación y el Objeto 3, recuperado en superficie, para ser observados en el microscopio de barrido electrónico (SEM) y obtener la composición química de los mismos. Dadas las pequeñas dimensiones del Objeto 2, decidimos efectuar los análisis destructivos solamente a los Objetos 1 y 3 . Se realizó un corte longitudinal y otro transversal en uno de los extremos de cada objeto con el fin de poder obtener dos fragmentos. Estos se incluyeron en baquelita conductora para confeccionar dos probetas metalográficas. Luego del pulido, ambas muestras se atacaron con una solución de amoníaco, agua oxigenada y agua destilada para ser observadas en el microscopio metalográfico, a cargo del Ing. Horacio de Rosa, Laboratorio de Materiales, Departamento de Ingeniería Mecánica (Facultad de Ingeniería - Universidad de Buenos Aires).

Realizamos el análisis por EDAX en las tres muestras utilizando el microscopio de barrido electrónico modelo SEM - FEI - Quanta 200 a cargo del técnico Matías Aldunate, Laboratorio de Microscopía Electrónica, Gerencia de Materiales (Comisión Nacional de Energía Atómica, Centro Atómico Constituyentes).

Tabla 1: Características de los materiales. Las dimensiones se expresan en largo, ancho y espesor.

\begin{tabular}{l|l|l|l}
\hline MATERIALES & RECOLECCIÓN - UBICACIÓN & DIMENSIONES & PESO \\
\hline Objeto 1 & Excavación - Sector A & $79,21-7,04-2,69 \mathrm{~mm}$ & $9,435 \mathrm{~g}$ \\
\hline Objeto 2 & Excavación - Sector A & $11,61-7,54-2,84 \mathrm{~mm}$ & $1,025 \mathrm{~g}$ \\
\hline Objeto 3 & Superficie - Sector A & $45,5-10,27-5,35 \mathrm{~mm}$ & $16,291 \mathrm{~g}$ \\
\hline Objeto 4 & Superficie - Sector A & $19,54-12,6-7,68 \mathrm{~mm}$ & $11,017 \mathrm{~g}$ \\
\hline Objeto 5 & Superficie - Sector B & $63,56-58,37-1,37 \mathrm{~mm}$ & $27,531 \mathrm{~g}$ \\
\hline Objeto 6 & Excavación - Sector A & $11,48-4,29-0,64 \mathrm{~mm}$ & $0,101 \mathrm{~g}$ \\
\hline
\end{tabular}




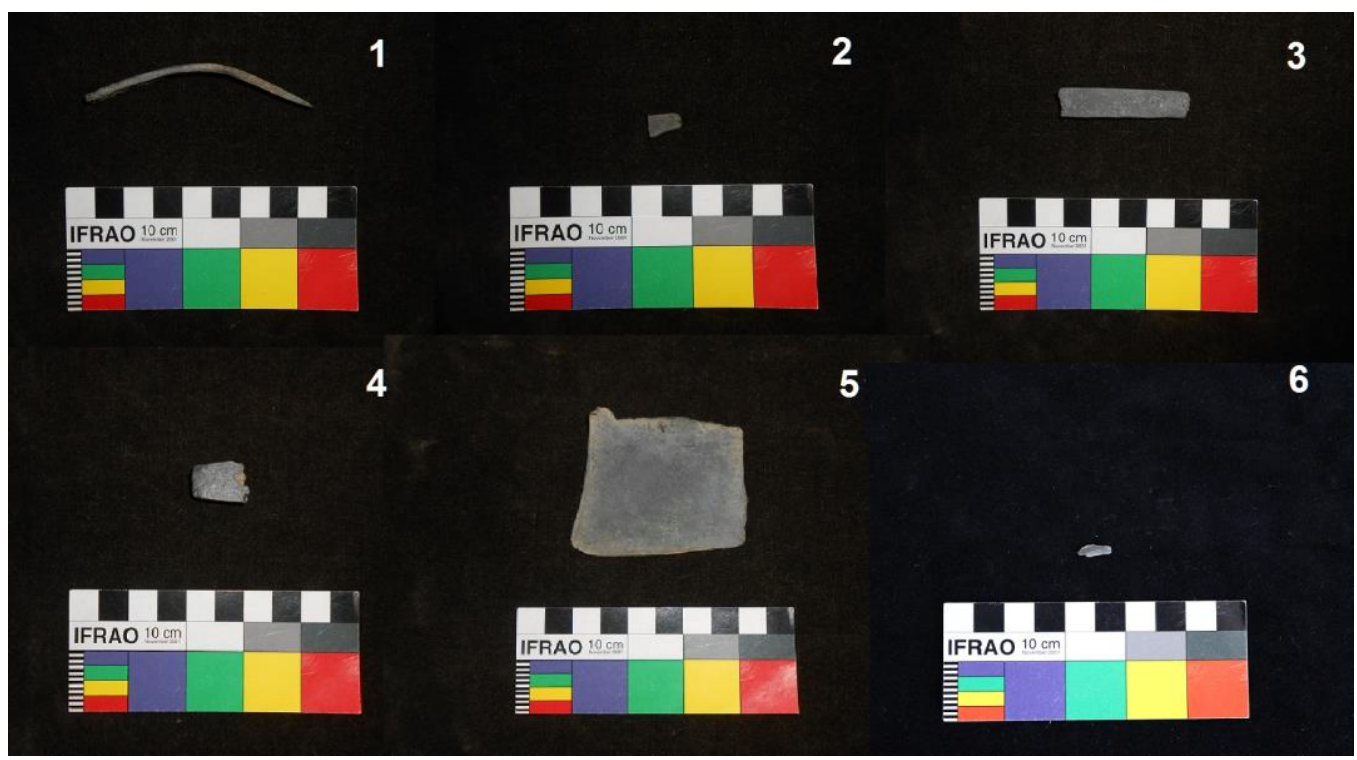

Figura 3: Materiales bajo estudio.

\section{RESULTADOS}

A través de la observación de las probetas en el microscopio metalográfico (Figura 4) pudimos determinar que el Objeto 1 y el Objeto 3 presentan una estructura de solución sólida de cobre con partículas de plomo asociadas con cierto contenido de bismuto. Los análisis de EDAX arrojaron resultados de composición química cercanos al 90\% de cobre en las probetas correspondientes al Objeto 1 y 3 (ver ANEXO). El Objeto 2 fue sometido al análisis por EDAX sin ser preparado como las probetas anteriores, por lo cual los resultados que arrojó son representativos de la situación real en la que se encuentran los artefactos hallados en contexto, ya sea en superficie o excavación. En la tabla adjunta en el anexo se puede observar la clara presencia de componentes como oxígeno, carbono, silicio, entre otros, producto de la corrosión superficial.

El revelado de la estructura del Objeto 1 presenta bandas de diferente coloración que podrían corresponder a un fenómeno de microsegregación. Se observa deformación no uniforme evidenciada por el tamaño de grano que va del orden de 5 a $30 \mu \mathrm{m}$. Las imágenes obtenidas en el microscopio de barrido electrónico no arrojaron diferencia de composición de fases, aun así, se realizó EDAX en las zonas comprendidas dentro y fuera del bandeado observado en el microscopio metalográfico y no se distinguieron diferencias significativas.

Por el contrario la probeta correspondiente al Objeto 3 presenta una estructura con granos de mayor tamaño y uniformes del orden de 100 a $200 \mu \mathrm{m}$. Se observó la presencia de inclusiones tanto en borde como dentro de los granos y marcas de deformación en la mayoría de la superficie analizada. En algunos sectores se distinguió la presencia de corrosión intergranular.
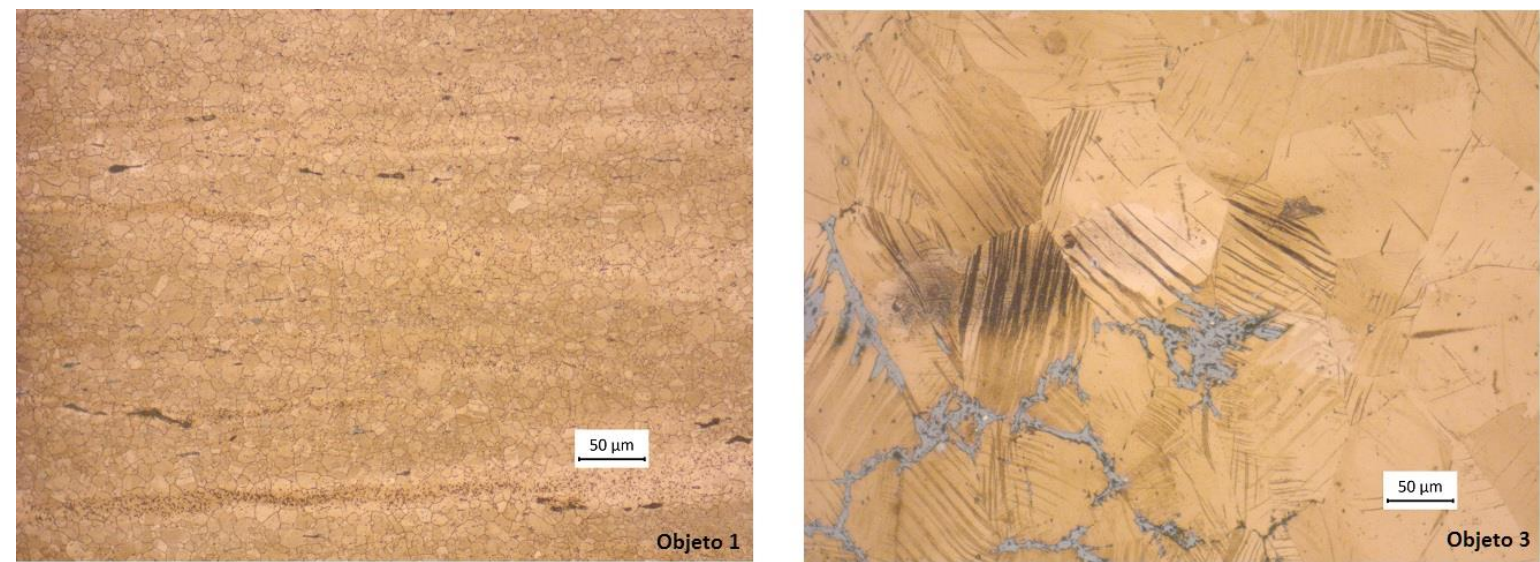

Figura 4: Metalografías de las probetas correspondientes a los Objetos 1 y 3. 


\section{DISCUSIÓN}

Se pudieron observar claras diferencias entre la manufactura de los Objetos 1 y 3 . El Objeto 1 presenta granos de tamaño no uniforme, probablemente debido a un proceso de conformado en caliente o a sucesivos pasos de deformación y calentamiento que generaron la recristalización del material. El conformado manual puede dar como resultado la estructura observable. Es decir, el material fue repetidamente expuesto a una fuente de calor y luego deformado (con martillo o alguna clase de percutor, por ejemplo). La direccionalidad del conformado de las bandas e inclusiones que se observan en la probeta no pudo diferenciarse en términos de composición de modo significativo. Esto permite inferir que sólo se manifiesta la deformación mecánica del artefacto y no así una distribución no uniforme de los componentes químicos. Por otra parte, el Objeto 3 presentó granos de mayor tamaño y evidentes marcas de deformación que interpretamos como resultado de un proceso de conformación a bajas temperaturas.

A partir de la caracterización macroscópica y de los análisis realizados no hemos podido determinar la funcionalidad que estos objetos tenían entre los pobladores prehispánicos que los manufacturaron. Aun así, hemos podido determinar que a pesar de presentar metalografías distintas, ambos artefactos fueron posiblemente manufacturados a partir de las mismas técnicas de conformado manual, siendo la exposición a altas o bajas temperaturas la condicionante en la recristalización de los granos. Además, los objetos cuentan con una composición química similar, ya sea consecuencia de la misma fuente de aprovisionamiento o producto de la molienda del mineral.

Resta analizar otros factores - presencia de plomo, microdureza - que pudieron afectar la conformación de los artefactos. La presencia de plomo en ambos objetos, con una proporción de alrededor del 10\% sobre el total, pudo haber alterado alguna propiedad metalúrgica del material; será parte de las futuras investigaciones indagar si esta característica es producto de un agregado intencional o está relacionada a la composición química de la fuente de aprovisionamiento. A su vez, la microestructura observada en las dos muestras pudo haber tenido claras consecuencias en términos de propiedades mecánicas, por lo cual consideramos realizar ensayos de microdureza para resolver esta problemática.

Además, se proyecta en los estudios subsiguientes investigar la apropiación del material, es decir, la extracción y acceso a las materias primas y su posterior procesamiento hasta llegar al momento de la manufactura. Dados los antecedentes de producción metalúrgica prehispánica en el sur de los valles Calchaquíes, sería conveniente realizar comparaciones para obtener una visión más completa de lo que sucedió de manera diacrónica.

\section{CONCLUSIONES}

Esta primera aproximación a los materiales metalúrgicos de Falda del Cerro permitió realizar una caracterización general de los mismos. El empleo del microscopio metalográfico, el microscopio de barrido electrónico (SEM) y los resultados del análisis por EDAX nos permitieron observar claras diferencias en la microestructura de las probetas en cuestión. El Objeto 1 presentó mayor deformación, evidenciada por el tamaño pequeño de los granos, y por el contrario, el Objeto 3 presentó granos de mayor tamaño y gran cantidad de marcas de deformación. A partir de esto podemos indicar que en los primeros siglos d.C. se utilizó cobre (88\% - 93\%), el cual sufrió diversos procesos de deformación a distintas temperaturas. No observamos evidencias de manufactura correspondientes únicamente a fundición, sino que posterior a la misma se trabajó para dar forma al objeto. Es importante indagar en el rol que cumplieron las inclusiones (por ejemplo, presencia de plomo) tanto como elementos capaces de alterar las propiedades mecánicas y físicas del material como vía para acceder a la identificación de posibles fuentes de aprovisionamiento que contaran naturalmente con estas impurezas.

Este trabajo preliminar busca ser el inicio de la investigación sobre los procesos metalúrgicos en el área. A partir de los análisis realizados hemos logrado acercarnos a las técnicas de manufactura utilizadas por las poblaciones que habitaron el sur de los valles Calchaquíes en los primeros siglos d.C.

\section{AGRADECIMIENTOS}

Este trabajo se financió con fondos de los subsidios ANPCyT PICT 2011 N $^{\circ} 633$ y CONICET-PIP 20122014 N $^{\circ} 486$ dirigidos por M. Cristina Scattolin. Quiero agradecer a Lucas Pereyra Domingorena y a Horacio de Rosa por su constante apoyo. Al Grupo de Arqueometalurgia de FIUBA, especialmente a Marcela Pichipil y a Marina Rañi. Al equipo técnico de la CNEA-CAC, Matias Aldunate y Patricia Bozzano. A la Lic. M. Cristina Scattolin por sus comentarios. 


\section{BIBLIOGRAFIA}

[1] MARQUEZ MIRANDA, F., CIGLIANO, E., "Problemas arqueológicos de la zona de Ingenio del Arenal", Revista del Museo de La Plata (Nueva Serie), v.25, pp. 123-169, 1961.

[2] SCATTOLIN, M.C., "Santa María antes del año mil. Fechas y materiales para una historia cultural", In: V. Williams, B. Ventura, A. Callegari y H. Yacobaccio, (eds.) Sociedades precolombinas surandinas: Temporalidad, interacción y dinámica cultural del NOA en el ámbito de los Andes Centro-Sur , pp. 203-219. Instituto de Arqueología - FFyL - UBA, 2007.

[3] SCATTOLIN, M.C., WILLIAMS, V., “Actividades minero-metalúrgicas prehispánicas en el noroeste argentino. Nuevas evidencias y su significación”, Bulletin de l'Institute Français d'Études Andines, v.21, n.1, pp. 59-87, 1992.

[4] LAZZARI, M., Traveling Things and the Production of Social Spaces: An Archaeological Study of Circulation, Value, and Material Culture in Northwestern Argentina (First millennium A.D.). Unpublished PhD dissertation. Anthropology Department, Columbia University, 2006.

[5] LAZZARI, M. Y., PEREYRA DOMINGORENA, L., "Revisitando Ingenio del Arenal- Faldas del Cerro (Catamarca): Relevamiento planimétrico y nuevos sondeos", In: XV Congreso Nacional de Arqueología, Problemáticas de arqueología contemporánea, Tomo II, pp. 761-764, 2008.

[6] AMBROSETTI, J.B. "El bronce en la región calchaquí", In: Anales del Museo Nacional de Buenos Aires, v.11 pp. 163-312, Buenos Aires, 1904.

[7] GONZALEZ, A.R. "La metalurgia precolombina del NOA. Secuencia histórica y proceso cultural", Actas Jornadas del Noroeste, Buenos Aires, Universidad del Salvador, pp. 88-136, 1979.

[8] SCATTOLIN, M.C., BUGLIANI, M.F. CORTES, L.I., et al., "Una máscara de cobre de tres mil años. Estudios arqueometalúrgicos y comparaciones regionales", Boletín del Museo Chileno de Arte Precolombino, v.15, n. 1, pp.25-46, 2010.

[9] ANGIORAMA, C. I. "La metalurgia del período formativo: El proceso de producción de objetos de metal en Condorhuasi-Alamito", Cuadernos del Instituto Nacional de Antropología y Pensamiento Latinoamericano, v. 16, pp. 241-260, 1995.

[10] ANGIORAMA, C. I. "Análisis de objetos de metal procedentes de Alamito", Mundo de Antes, n. 2, pp. 25-35, 2001.

[11] GONZALEZ, L. R. "A sangre y fuego. Nuevos datos sobre la metalurgia Aguada", Estudios atacameños, n. 24, pp.21-37, 2002.

[12] GONZALEZ, L. R. "Heredarás el bronce. Incas y metalurgia en el Sur del valle de Yocavil”, In: Intersecciones en Antropología, n. 3, pp. 55-68, 2002.

[13] GONZALEZ, L.R., Bronces sin nombre. La metalurgia prehispánica en el Noroeste Argentino, Buenos Aires, Ediciones, Fundación CEPPA, 2004.

[14] GONZALEZ, L. R. "Tradición tecnológica y tradición expresiva en la metalurgia prehispánica del Noroeste argentino", Boletín del Museo Chileno de Arte Precolombino, v. 12, n. 2, pp. 33-48, 2007.

[15] GONZALEZ, L. R. "Fuegos sagrados. El taller metalúrgico del sitio 15 de Rincón Chico (Catamarca, Argentina)", Boletín del Museo Chileno de Arte Precolombino, v. 15, n. 1, pp. 47-62, 2010.

[16] GLUZMAN, G. A. "Representación humana y género en piezas de metal del Noroeste argentino", Boletín del Museo Chileno de Arte Precolombino, v.15, n. 2, pp. 89-106, 2010.

[17] GLUZMAN, G. A. "Producción metalúrgica y dinámica social en el Noroeste argentino (Siglos XII XVII)”, In: Arqueología, Instituto de Arqueología, FFYL-UBA, v. 18, pp. 319-322, 2012. 


\section{ANEXO}

\section{Objeto 1}

1.1. Composición química de la muestra.

1.2. Análisis de EDAX.

1.3. Imágenes SEM.

\begin{tabular}{l|l|l}
\hline ELEMENTO & WT \% & AT \% \\
\hline MgK & 01.90 & 05.15 \\
\hline CuK & 88.59 & 91.82 \\
\hline PbL & 09.51 & 03.02 \\
\hline
\end{tabular}
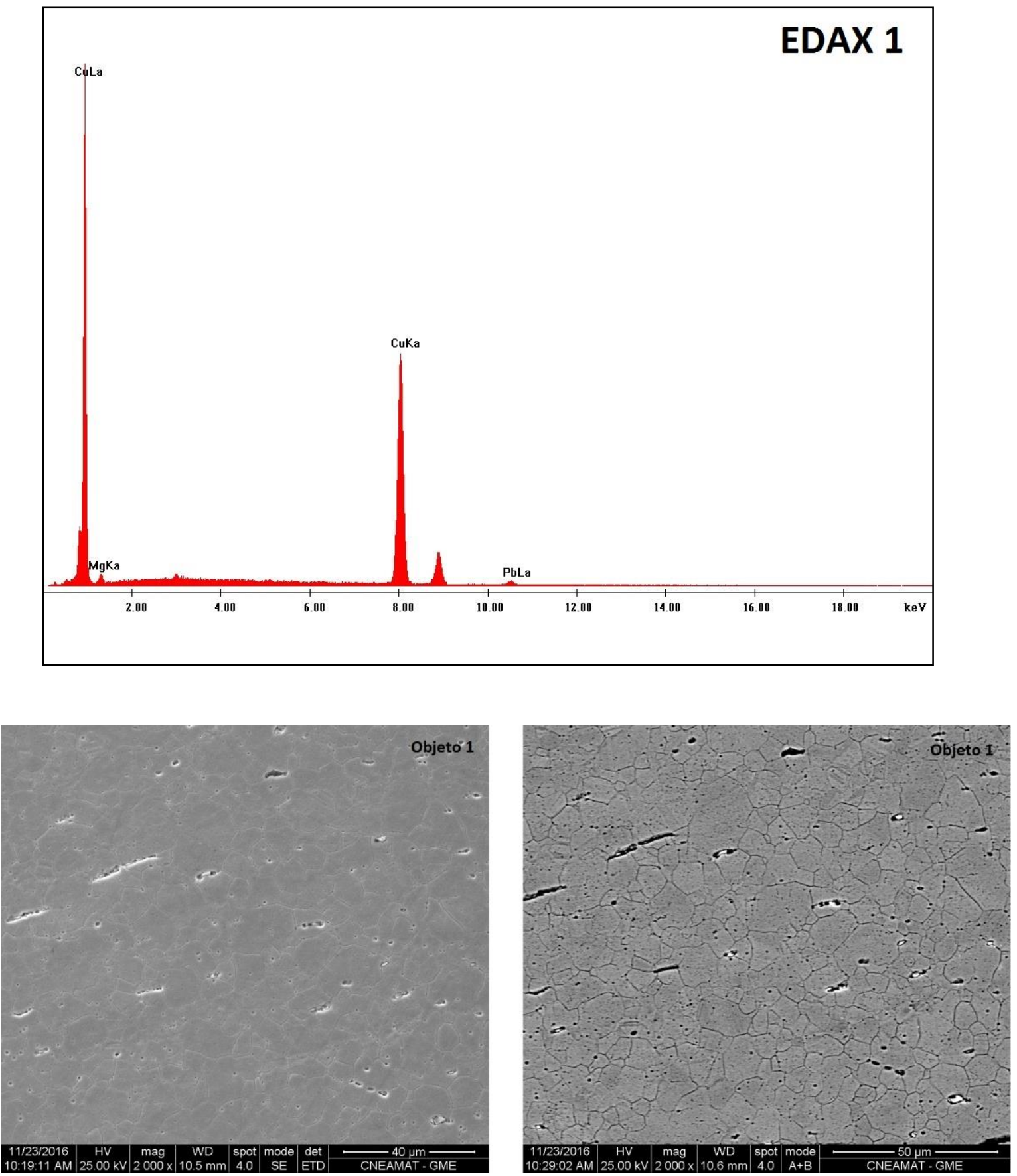


\section{Objeto 2}

2.1. Composición química de la muestra

2.2. Análisis de EDAX.

2.3. Imágenes SEM.

\begin{tabular}{l|l|l}
\hline ELEMENTO & WT\% & AT\% \\
\hline C K & 10.97 & 19.34 \\
\hline O K & 39.98 & 52.91 \\
\hline MgK & 00.97 & 00.85 \\
\hline AlK & 04.10 & 03.22 \\
\hline SiK & 20.23 & 15.25 \\
\hline P K & 00.50 & 00.34 \\
\hline K K & 00.43 & 00.23 \\
\hline FeK & 01.07 & 00.57 \\
\hline CuK & 01.05 & 00.40 \\
\hline & 20.69 & 06.89 \\
\hline
\end{tabular}
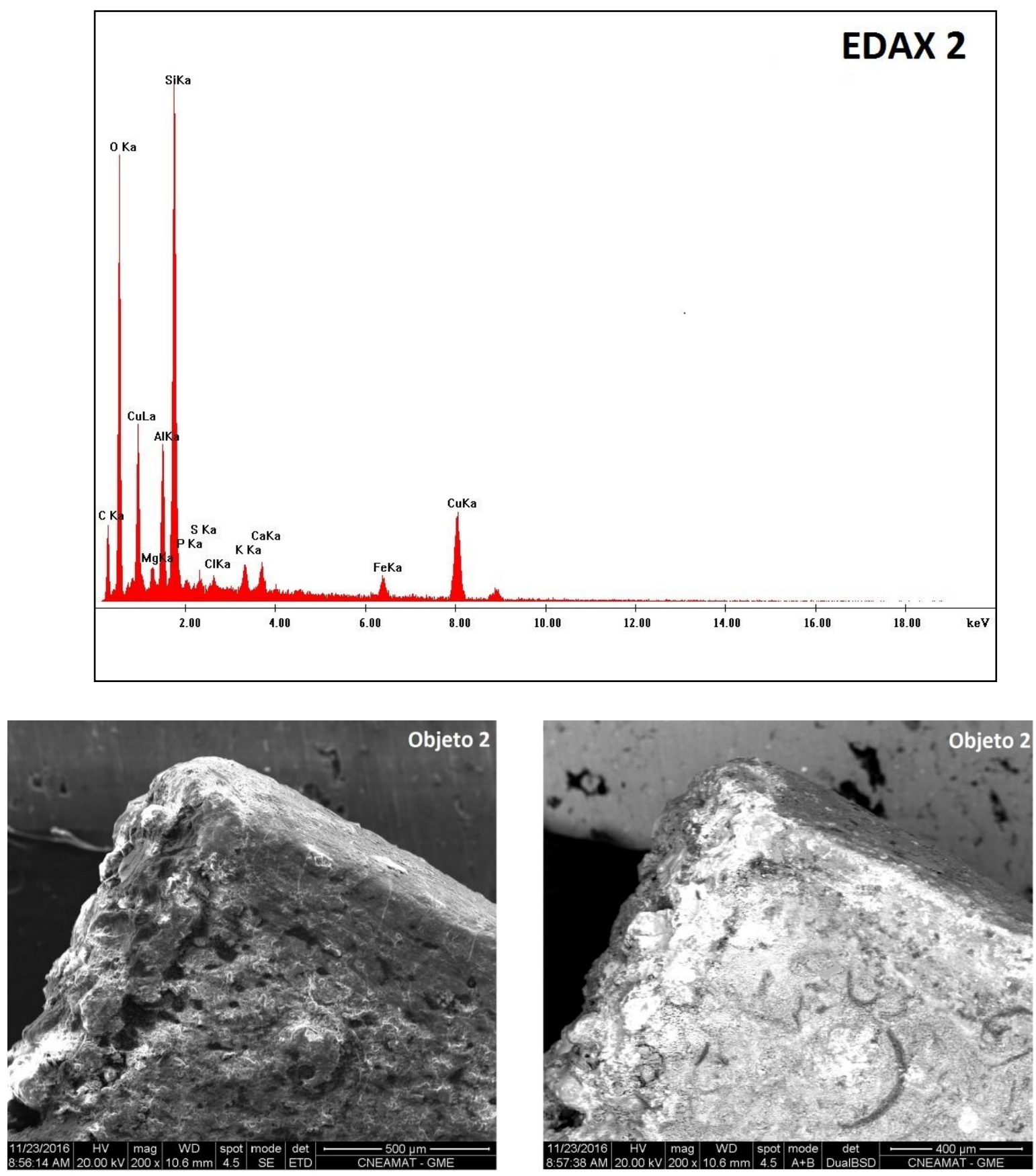


\section{Objeto 3}

3.1. Composición química de la muestra.

3.2. Análisis EDAX.

3.3. Imágenes SEM.

\begin{tabular}{l|l|l}
\hline ELEMENTO & WT $\%$ & AT $\%$ \\
\hline MgK & 01.21 & 03.22 \\
\hline CuK & 93.33 & 95.07 \\
\hline PbL & 05.46 & 01.71 \\
\hline
\end{tabular}
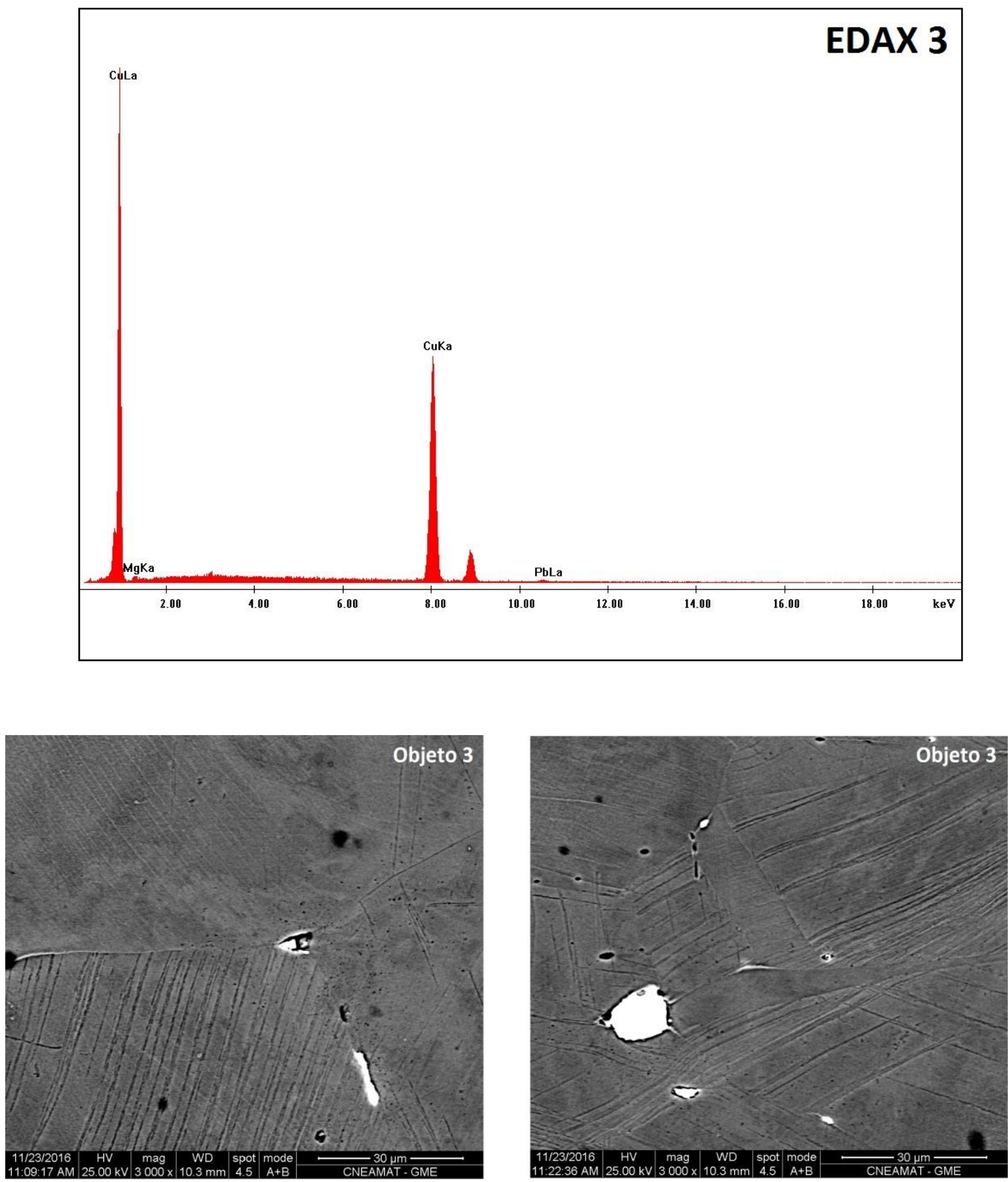